ISSN 2413-0877 Volume 2 (2015) 427-432

The 3rd International Conference on Biological Science 2013

(The 3rd ICBS-2013)

\title{
DIVERSITY OF MICROBIAL ENDOPHYTES IN THE STEM AND STEM WATER OF Ceiba pentandra
}

\author{
Rina Hidayati Pratiwi \\ University of Indraprasta PGRI, Postgraduated student at University of Indonesia. \\ Correspondence author: rina.hp2012@gmail.com
}

\begin{abstract}
Ceiba pentandra (Kapok trees) serve the purpose of drug which we know as tribal medicine. Based on research before, most of secondary metabolites were found in the stem and stem water of $C$. pentandra which could produce antimicrobial compounds against Staphylococcus aureus and Escherichia coli. Nevertheless, little is known about the diversity of endophytic microorganisms inhabit the stem and stem water of $C$. pentandra and their potential to produce bioactive compounds. The purpose of this work was to know the diversity of endophytic microorganisms inhabited the stem and stem water of $C$. pentandra. The microbes were isolated from the stem and stem water of $C$. pentandra. The endophytes were characterized based on the morphology appearance of the microbial endophytes microscopical and macroscopical. From the samples of stem water, 278 isolates of the microbial endophytes grew at NA medium and 31-257 isolates at PDA medium whereas from stem, 4 isolates of the microbial endophytes grew at NA medium and 2 isolates at PDA medium. When identified morphologically and biochemically, only 7 colonies at stem water and 5 colonies at stem had showed identifiable differences. Among the microbial group the most frequently in endophytic association with stem water may it be khamir. Meanwhile, bacteria was the most frequently in endophytic association with stem. This research indicated that culturable endophytes in the stem and stem water of $C$. pentandra were very diverse. Microbial endophytes are suggested as an outstanding source of bioactive natural products that could be useful for medicines.
\end{abstract}

Keywords: Ceiba pentandra, microbial endophytes, diversity

\section{INTRODUCTION}

Ceiba pentandra (Bombacaceae) commonly called Kapok tree or silk cotton (English), Rimi (Hausa, Nigeria), Vamber (Tiv, Nigeria), King (Yandang, Nigeria) is grown chiefly in Asia and Indonesia. C. pentandra is an important product of Java (Doughari \& Loryue 2009). C. pentandra originated in the American tropics. Its natural distribution has been obscured by its widespread introduction after about 1500. It is now cultivated all over the tropics, but mainly in South-East Asia, especially in Indonesia and Thailand (Probase Record).

C. pentandra finds wide application in Indonesia especially Banten. The root and stem barks are credited with emetic and antispasmodic properties. Stem bark decoctions are used in mouth washes for treating toothache and mouth problems, and are taken to treat stomach problems, diarrhoea, hernia, gonorrhoea, heart trouble, oedema, fever, asthma and rickets; they are also applied on swollen fingers, wounds, sores, furuncles and leprous macules. Leaf preparations are used as an eye-bath to remove foreign bodies from the eye. A decoction of the leaves and water of the stem is applied to treat conjunctivitis and wounds in the eye, and is used for bathing and massage to treat fever (Probase Record).

Secondary metabolites occur in plants in a high structural diversity. Biochemical and physiological features of secondary metabolism are strongly correlated with its function. Secondary metabolites are not useless waste products but important means of plants for de-

ISSN 2413-0877 (C) 2015 The Authors.

Published by KnowledgeE Publishing Services This is an open access article under the CC BY-NC-ND license (http://creativecommons.org/licenses/by-nc-nd/4.0)

Selection and Peer-review under responsibility of the 3rd ICBS-2013

Doi http://dx.doi.org/10.18502/kls.v2i1.187 
fense against herbivores, microbes (bacteria, fungi) and viruses. Land plants have evolved secondary metabolites with a wide repertoire of biochemical and pharmacological properties (Wink, 2011).

Numerous natural products from $C$. pentandra show striking structural similarities to known secondary metabolites. C. pentandra shows the presence of many chemical constituents which are responsible for varied pharmacological and medicinal property (Elumalai et al. 2012). Based on Anosike et al. (2012), the methanol extract of $C$. pentandra stem bark showed activity against all test isolates with highest activity against the fungi (Candida albicans and Aspergillus niger) and also had a higher activity on the Gram positive bacteria as compared to Gram negative bacteria. The ethanol and the petroleum ether extract of that had a higher activity on Escherichia coli and Bacillus subtilis and minimal activity on the fungi for the ethanol extract. Meanwhile, Bairwa et al. (2011) had reported the protective activity of ethyl acetate fraction of methanol extract of stem bark of $C$. pentandra against paracetamol-induced liver damage in rats. The phytochemical studies of the methanolic extract revealed the presence of saponins, flavonoids, tannins, terpenes, resins and carbohydrates (Sule et al. 2009).

However, production of secondary metabolites from plants is not always satisfactory. It is often restricted to a limited species or genus, and geographically to a specific region. Many important medicinal plants were endangered by overexploitation (Manuhara, 2011). As like Ceiba pentandra. This plant is difficult to cultivate and grow very slowly or are endangered in their natural habitats. To avoid that, many efforts for getting the secondary metabolites without overexploitation. An alternative effort for the production of plant materials for secondary metabolite production is the exploration and isolation of the endophytic microbial.

Every plant-species constitutes a possible host for endophytic microorganisms, which, in the vast majority and despite their biotechnological potential (Ezra et al. 2004), remain unidentified. Nevertheless, little is known about the diversity of endophytic microorganisms inhabit the stem and stem water of $C$. pentandra and their potential to produce bioactive compounds. It is therefore interesting to investigate the antimicrobial activity of the endophytic microbial of the part of plant especially stem and stem water against some pathogenic bacteria. The aim of this research was to know the diversity of endophytic microorganisms inhabit the stem and stem water of $C$. pentandra.

\section{MATERIALS AND METHODS}

The samples of $C$. pentandra were collected from the village around Lebak district, Banten. The bark was removed manually and dried, debarked logs were prepared into chips of suitable size that remain between $2-5 \mathrm{~mm}$. For getting stem water, stem were cut using sterile machete and taken to the laboratory in sterile containers at temperature of $4{ }^{\circ} \mathrm{C}$. The endophytic microbial of the $C$. pentandra was screened and characterized based on the morphology appearance of the endophytes microscopical and macroscopical. Purified strains were characterised using morphological and biochemical tests according to standard methods: catalase test and oxidase test. Cell morphology, gram stain and motility were observed using light microscopy. 
Prior to analysis, each sample was tested againsts the indicator strains of bacteria, they are Escherichia coli, Staphylococcus aureus, and Bacillus cereus. The agar well diffusion method was performed to exploit antibacterial potential (Bibi et al. 2010). Each endophytic microbial was tested the viability of antibacterial activity for E. coli, S. aureus, and B. cereus. Boric acid 10\% (5.7 g/ $100 \mathrm{~mL})$ in aquadest was prepared as positive control. Pure DMSO (99.9\%) was used as negative control. Drops of culture (48 hours for bacteria and 4-5 days for fungi) of each tested strain were spotted onto agar plates seeded with active growing cells of the indicator organism. After incubation ( 24 hours at $37^{\circ} \mathrm{C}$ ), the antimicrobial activity was determined as a clear zone of inhibition around the spots. Isolates showing ability to produce antibacterial compounds were chosen for further analysis.

\section{RESULTS AND DISCUSSION}

Endophytic microbial were isolated from different parts of $C$. pentandra. The microbial population of stem water ranged from $2.78 \times 10^{6}$ to $1.23 \times 10^{8} \mathrm{CFU} . \mathrm{g}^{-1}$ on the NA plates and from 31 to 257 on the PDA plates (Table 1). Among all the isolates on the NA plates and the PDA plates, colonies were chosen according to their morphological differences on each NA plate and PDA plate. More colonies were chosen from the higher population of culturable bacteria on each of the NA plates and PDA plates. The total of endophytic microbial densities recorded from the surface of the $C$. pentandra indicate slight differences in the numbers of viable bacteria isolated from different parts (stem and stem water). The number of endophytic microbial that isolated from stem water are higher than those isolated from stem, which could suggest that the endophytic microbial more inhabit the stem water than the stem of $C$. pentandra.

Table 1. Endophytic microorganisms that isolated from the stem and stem water of Ceiba pentandra

\begin{tabular}{cccccc}
\hline $\begin{array}{c}\text { The type } \\
\text { of } \\
\text { samples }\end{array}$ & $\begin{array}{c}\text { The } \\
\text { type of } \\
\text { medium }\end{array}$ & $\begin{array}{c}\text { The total } \\
\text { of } \\
\text { colonies }\end{array}$ & $\begin{array}{c}\text { The } \\
\text { total of } \\
\text { isolates }\end{array}$ & $\begin{array}{c}\text { The group } \\
\text { of } \\
\text { microbes }\end{array}$ & Notes \\
\hline Stem & NA & 278 & 3 & bacteria & B1, B2, B3 \\
Water & PDA & $31-257$ & 4 & khamir & SP4, SP6, SP7, SP9 \\
Stem & NA & 4 & 4 & bacteria & BN1, BN2, BN3, BN4 \\
& PDA & 2 & 1 & kapang & BP1 \\
\hline
\end{tabular}

The endophytic microbial of the $C$. pentandra was found in stem and stem water. At the stem water, four of which were identified as khamir, three of which were identified as bacteria. At the stem, four of which were identified as bacteria and one of which was identified as kapang. Endophytic communities are formed mainly by fungi and bacteria. Although the interaction between these microorganisms and their respective host-plants is not, as yet, fully understood, over recent years they have been progressively more extensively employed, either in agriculture (Ryan et al., 2008), or in the production of compounds with therapeutic application, such as taxol (Stierle et al., 1993) and leucinostatin A (Strobel \& Hess 1999). Literature data reporting, 16 isolates of the endophytic microbial were obtained at $C$. pentandra, although, when compared to sequences deposited in GenBank, only seven had produced identifiable fragments. They are Bacillus anthracis, Bacillus cereus, Bacillus thuringiensis, Bacillus sp. that isolated from the seed of $C$. pentandra (Coelho et al., 2011). 
The endophytic microbial from C. pentandra was assayed for their antimicrobial activity against the indicator strains of bacteria. Antimicrobial activity of endophytic microbial from stem and stem water of $C$. pentandra was found in several isolates (Table 2). At the stem water, two of khamir (SP6 and SP9) and bacteria (B2 and B3) have antibacterial activity. At the stem, all of bacteria isolates have antibacterial activity. One strain of khamir obtained from the stem water (SP6) only produced antibiotic compounds active against $E$. coli whereas one strain of that (SP9) produced antibiotic compounds active against $S$. aureus and $B$. cereus. Different with bacteria, one strain of bacteria (B2) produced antibiotic compounds active against both $E$. coli and B. cereus isolates while the strain of B3 only produced antibiotic compounds active against $B$. cereus. Meanwhile, the strains of bacteria that obtained from the stem of $C$. pentandra, like BN2 have a clear zone of inhibition for S. aureus; BN4 for E.coli and B.cereus; and BN3 for all of indicator strains of bacteria.

Table 2. The test of antibacteria activity from endophytic microorganisms that isolated

\begin{tabular}{|c|c|c|c|c|c|}
\hline \multirow{2}{*}{$\begin{array}{l}\text { The type } \\
\text { of } \\
\text { samples }\end{array}$} & \multirow{2}{*}{$\begin{array}{c}\text { The type of } \\
\text { isolates }\end{array}$} & \multirow{2}{*}{$\begin{array}{l}\text { The group } \\
\text { of microbes }\end{array}$} & \multicolumn{3}{|c|}{ The zones of inhibited $(\mathrm{cm})$} \\
\hline & & & E. coli & S. aureus & B. cereus \\
\hline Stem & SP4 & Khamir & 0 & 0 & 0 \\
\hline \multirow[t]{5}{*}{ Water } & SP6 & & 0.8 & 0 & 0 \\
\hline & SP7 & & 0 & 0 & 0 \\
\hline & SP9 & & 0 & 0.7 & 0.8 \\
\hline & Kontrol (+) & & 1.3 & 1.2 & 1.8 \\
\hline & Kontrol (-) & & 0 & 0 & 0 \\
\hline Stem & B1 & Bacteria & 0 & 0 & 0 \\
\hline \multirow[t]{4}{*}{ Water } & B2 & & 0.7 & 0 & 0.7 \\
\hline & B3 & & 0 & 0 & 0.8 \\
\hline & Kontrol (+) & & 0.9 & 1.2 & 1.0 \\
\hline & Kontrol (-) & & 0 & 0 & 0 \\
\hline \multirow{5}{*}{ Stem } & BN2 & Bacteria & 0 & 0.7 & 0 \\
\hline & BN3 & & 0.7 & 0.7 & 0.7 \\
\hline & BN4 & & 0.7 & 0 & 0.7 \\
\hline & Kontrol (+) & & 0.9 & 1.1 & 0.9 \\
\hline & Kontrol (-) & & 0 & 0 & 0 \\
\hline
\end{tabular}

Strain SP6 formed slow-growing, smooth-rising, small-sized, pink-pigmented colonies. It had a spherical shape of the colony. Strain SP9 formed slow-growing, unsmooth-rising, small-sized, white-coloured colonies. It had a spherical shape of the colony. Strain B2 and B3 was characterised as a Gram-negative, white-coloured colonies, irregular round shape and irregular rod shape. Strain BN2 was characterised as a Gram-negative, regular bumpy round shape, and white-coloured colonies. Strain BN3 and BN4 was characterised as a Gram-positive, white-coloured colonies. They had a irregular round shape and irregular rod shape of the colony.

The SP9 isolates of khamir demonstrated antibacterial activity against both $S$. aureus and $B$. cereus demonstrating a higher activity than another. Meanwhile, the B2 isolates of bacteria demonstrated antibacterial activity against both $E$. coliand B. cereus. In this work, BN3 isolates have broad spectrum more of antibacterial activity than another. Strain BN3 revealed an indication that the endophytic microbial of $C$. pentandra contains secondary metabolites that have broad spectrum of antibacterial activity. This is actually a very significant discovery giving hope for the possible development of a novel endophytic from C. pentandra that can be effective in controlling multidrug resistant bacteria and a variety of other bacterial disease agents. The results of antimicrobial activity suggest that SP6, B2, 
BN4, and BN3 had the presence of tannins, alkaloids, saponins, flavonoids, sterols and or triterpenes and reducing sugars because antidiarrhoeal properties of medicinal plants were found to be due to that (Longanga et al., 2000).

In conclusion, results of this study revealed the presence of the endophytic microbial in the stem and stem water of $C$. pentandra. Endophytic communities are formed mainly by fungi (khamir and kapang) and bacteria. Endophytic microbial of the stem water of $C$. pentandra are higher of the number than the stem. Neverthelles, endophytic microbial of the stem showed broad spectrum more of antibacterial activity than endophytic microbial of the stem water of $C$. pentandra. However, the results of this research could be references more about the diversity of endophytic microorganisms inhabit the part of $C$. pentandra.

\section{ACKNOWLEDGMENT}

Authors gratefully acknowledge DIKTI that gave grants during the research. This work was supported by the University of Indraprasta PGRI.

\section{REFERENCES}

Anosike, C.A., O.B. Ogili, O.N. Nwankwo, and E.A. Eze. 2012. Phytochemical screening and antimicrobial activity of the petroleum ether, methanol and ethanol extracts of Ceiba pentandra stem bark. J Med Plants Res 6(46): 5743-5747.

Bairwa, N.K., K. Sethiya, and S.H. Mishra. 2011. Protective effect of stem bark of Ceiba pentandra Linn. against paracetamol-induced hepatotoxicity in rats. Phcog Res 2: 2630.

Bibi, Y., S. Nisa, A. Waheed, M. Zia, S. Sarwar, S. Ahmed, and M.F. Chaudhary. 2010. Evaluation of Viburnum foetens for anticancer and antibacterial potential and phytochemical analysis. Afri J Biotechno/9: 5611-5615.

Coelho, M., M.F. Nozawa, M.S. Nozawa, S.R. Santos, and L.W. Andre. 2011. Isolation of endophytic bacteria from arboreal species of the Amazon and identification by sequencing of the 16S rRNA encoding gene. Genetics and Molecular Biology 34(4): 676-680.

Doughari, J.H., and A.S. Ioryue. 2009. Antimicrobial Activity of Stem Bark Extracts of Ceiba pentandra. Pharmacology. 1:1333-1340.

Elumalai, A., N. Mathangi, D. Adarsh, K. Raju, and V. Yetcharla. 2012. A review on Ceiba pentandra and its medicinal features. Asian J Pharm Tech 2(3): 83-86.

Ezra, D., U.F. Castillo, G.A. Strobel, W.M. Hess, H. Porter, J.B. Jensen, M.A.M. Contron, D.B. Teplow, J. Sears, and M. Maranta. 2004. Coronamycins, peptide antibiotics produced by a verticullate Streptomyces sp. (MSU-2110) endophytic on Monstera sp. Microbiology 150: 785-793.

Longanga, O.A., A. Vercruysse, and A. Foriers. 2000. Contribution to the Ethnobotanical, Phytochemical and Pharmacological studies of traditionally used medicinal plants in the treatment of dysentery and diarrhea in Lomela area, Democratic Republic of Congo (DRC). J of Ethnopharmacology 71(3):411-23. 
Manuhara, Y.S.W. 2011. Plant Hairy Root Culture: A Promising System to Produce Secondary Metabolite. Department of Biology, Faculty of Science and Technology. Airlangga University, Surabaya.

Protabase Record. Prota 16: Fibres/ Plantes à fibres. Record display. http://database. prota.org/ PROTAhtml/ Ceiba pentandra_En.htm.

Ryan, R.P., K. Germaine, A. Franks, D.J. Ryan, and D.N. Dowling. 2008. Bacterial endophytes: Recent developments and applications. FEMS Microbiol Lett 278: 1-9. Stierle A, Strobel G, Stierle D. 1993. Taxol and taxane production by Taxomyces andreanae, an endophytic fungus of Pacific Yew. Science 260: 214-216.

Strobel, G., and W.M. Hess. 1999. Glucosylation of the peptide leucinostatina A, produced by an endophytic fungus of European yew, may protect the host from leucinostatin toxicity. Chem Biol 4:529-536.

Sule, M.I., N.S. Njinga, A.M. Musa, M.G. Magaji, and Abdullahi. 2009. Phytochemical and antidiarrhoeal studies of the stem bark of Ceiba pentandra (Bombacaceae). Nigerian J Pharm Sci 8(1): 143-148.

Wink, M. 2011. Occurrence and Function of Natural Products in Plants. Phytochemistry and Pharmacognosy. 